5o The Public and Is Problems, Nueva York, Henry Holt, 1927, p. 216. La cursiva es mía. (Citado por R. Bernstein en Philomphical Profiles, p. 270.)

"En Escuela y sociedad, por ujemplo, Dewey relaciona muy bien la revolución industrial con la necesidad de una refurma educativa. Según él, en cl pasado, cuando los bienes se producían artesanalmente o por lo menos en los talleres artesanales de los vecindarios, los niños podian observar procesos, primero bajo la forma de juego e imitación, luego casi como un aprendizaje, en toda clase de actividades y servicios sociales. Por consigaiente, fuera de la croucla propiamente dicha se contaba con otra escuela de la socialidad y del catacter y por eso la escuela podia limitarse a ensenat las pocas habilidades que dificilmente podian aprenderse de mudo espontáneo en el ambientc de los adultos o los coctáneos. Como la revolución industrial ha climinado esto, la escuela debla organizarse de manera tal que ofreciera la variedad de experiencias productivas y sociales que ya no se pueden recoger fucra de ellas. Sobre estos problemas véase W. Feinberg, «The Conflict Between Intelligence and Community in Dowey's Educational Philoxophy» $y$ «PJogressive Education and Social Planning»; C. Karier y D. Hogan, «Schooling, Education and the Structure of Social Reality» y R. Goodonow, "Racial and Ethnic Tolerance in John Dewey's Educational and Social Thought. The Depression Ycars", todos ellos tn fos volumenes II y III de John Dewey. Critical Assessments.

*2 "La prioridad de la democracia... $*$, p. 52 .

53 Textos citados por Wright Mills en Sociologia y pragmatismo, p. 462 . Véase en detalle los textos que eita Wright Mills en los que Dewey niega la presencia de lazos comunitarios en las organizaciones mafiosas. 54 Mbid. p. 459 .

\title{
La piedad en Rousseau: de la pasión a la virtud
}

\author{
AURELIO ARTETA \\ Departamento de Ética y Filosofía Politica \\ Universidad del País Vasco
}

Una advertencia al lector: que no espere hallar aquí más de lo que dice el título. Así que le doy por introducido en el largo e intrincado tratamicnto que la compasión ha merecido en la historia de las ideas. Dejaré también de lado, salvo de pasada, toda referencia a los vínculos que deberían resaltarse entre la doctrina de Rousseau y otras concepciones de la piedad, sean la clásica de Aristóteles o las posteriores de Schopenhauer o Nictzschc. Incluso sin entrar en debate con sus varios intérpretes, he de contentarme con restablecer los hitos mayores de un pensamiento que en este punto no siempre parece libre de ambigüedad.

\section{La morale du coeur}

Aquella moral del corazón que invocaban las ultrajadas heroinas de los relatos del marqués de Sade en súplica de piedad, y que sólo suscitaba la burla de sus verdugos, es justamente la moral propuesta por Rousseau. La misma que Julie, la heroína triunfante de La nouvelle Helö̈se, proclama seguir como regla de conducta más segura 1 . Se trata de una moral que descansa en la precedencia de los sentimientos y que hace de la piedad una de sus piedras angulares. Del todo opuesto a la doctrina de Sade, para Rousscau la compasión es un afecto primario inscrito en la naturaleza humana y al que sólo las leyes o conven- 
ciones de los hombres -o sca, las formas del amor propio nacidas de la civilización- pucden sofocar. «Los hombres son malos: una triste y continua experiencia nos dispensa de probarlo; sin cmbargo, el hombre es bueno por naturaleza...» (DD, n. IX, p. 239). La causante de su depravación es la sociedad.

$Y$ es que, de igual modo que cl hombre físico precede al metafísico o moral, nuestra sensibilidad es anterior a nucstra inteligencia y hemos tenido sentimientos antes que ideas. Tambión en el orden estrictamente moral la pugna entre la razón y el sentimiento se inclina a favor de este último: ssi c'est la raison que fait l'homme, c'est le sentiment qui le conduits $(N H$, III, 7). El preceptor de Emilio sólo infunde principios tcóricos de conducta en su discípulo tras haber procurado despertar en êl las emociones del hombre de la naturaleza. Al fin y al cabo, como diría el vicario saboyano, la conciencia se expresa en sentimientos, y no a través de juicios; $o$, por decirlo de otro modo, los afcctos naturales son los que constituyen la conciencia misma, ese «sentimiento interior» que cs para la acción un guía más fiable que los altos principios de la filosofia. Si las reglas morales están grabadas por la naturaleza en ol corazón humano, la moratidad de nuestros actos reside en el juicio inmediato que de ellos nos formamos. En esta materia somos nuestros propios jueces y no hay otras normas que las que nos marcan nuestras inclinaciones.

Pues bien, basta examinar estas inclinaciones para concluir que la bondad moral está conforme con nucstra naturaleza. Quienes insisten en que todo nos es indiferente salvo nuestro interés, no sólo zapan con él los fundamentos de la sociedad; más grave aún es su voluntad de ignorar lo que la voz de la concicncia nos indica sin ningún género de dudas. «¿Qué nos es más dulce de hacer y deja en nosotros una impresión más agradable una vez hecho, un acto de bencficcncia o un acto de maldad? $\$(E, 388)$. No hay nación ni epoca ni individuo, por degencrados que sean, que hayan llamado bueno a lo que es malo o que hayan preferido el crimen a la virtud. Sólo el interés personal que ciega a los malvados o la insinceridad de que adolecen algunos sabios - y cntre ellos Rousseau incluye a Montaigne-puede conducirles a pretender lo contrario. «Hay, pues, en el fondo de las almas un principio innato de justicia y virtud por el cual, a pesar de nuestras propias máximas, juz:gamos nuestras acciones y las de los demás como buenas o malas" (ibid., 310). Y si tal principio a sentimiento natural del hombre en relación consigo mismo se llama amor de sí, el que regula la relación con sus semejantes es la piedad.

\section{Naturaleza de la pitié}

Se sabe cómo caracteriza Rousseau este sentimiento al que tambien denomina virtud: es aquel «principio (...) quc, habiéndosele dado al hombre para suavizar, en determinadas circunstancias, la ferocidad de su amor propio o cl deseo de conservarse antes de que naciera en él ese amor templa el ardor con que mira por su bienestar mediante una repugnancia innata a ver sufrir a su semcjante» $(D D, 171)$. La pitié se define, ante todo, en forma negativa. Primero, porque consiste en un rechazo del sufrimiento ajeno, esto cs, porque delata más su carácter de aversión que de atracción hacia su objeto. Después, porque se dirige con preferencia a la debilidad humana, tal como se pone a prueba en las enfermedades o en la vejez. Y de ahi, en fin, que la piedad resulte incapaz de alcanzar la sublimidad expresada en el mandamiento Haz a los demás lo que quisieras para ti y deba atenerse a la máxima más asequible de Procura tu bien con el menor mal posible para tu prójimo. 
Pero aquella negatividad de la compasión se muestra, asimismo, en el hecho de que aparece como una instancia, cuya función primera y peculiar estriba en oponerse a otros sentimientos tan primarios como ella misma. La piedad surge para suavizar o templar el amor de sí y el amor propio, pero con una diferencia esencial que nace de la distinta naturaleza de cada uno de estos principios. El amour de soi, que no es sino el deseo de la propia conservación, tiene en la piedad su principio moderador, pero siempre complementario; aunque sea susceptible de exceso, el amor de sí es siempre bueno (y tanto que hasta se confunde con el amor al Creador. $E$, 425) y arraiga en la naturaleza humana originaria al igual que la piedad. Ésta, en cambio, ostenta un rango muy superior al de amour propre, que es a la postre un sentimiento gestado en la sociedad y artificialmente derivado del amor de sí; frente a ese amor propio, que tiende a encerrar a cada individuo en él mismo y a elevarlo por encima de todos los demás - - y que por ello es la raiz de todos los males que los hombres recíprocamente nos infligimos, la piedad habrá de emplearse mucho más a fondo. «El amor de si, que sólo nos afecta a nosotros, se contenta cuando nuestras verdaderas necesidades son satisfechas, pero el amor propio, que se compara, nunca está contento y no podría estarlo, porque ese sentimiento, al preferimos a los demás, exige también que los demás nos prefieran a sí mismos, lo cual es imposible. Así es como las pasiones suaves y afectuosas nacen del amor de sí y como las pasiones rencorosas e irascibles nacen del amor propio» ( $E, 285)$. En resumen, amor de sí y piedad -más que oponerse- se distinguen tan sólo por ser afectos de naturaleza respectivamente individual y social; piedad y amor propio se enfrentan porque, siendo ambos sentimientos relativos o referidos a los otros (y no a uno mismo), la una resulta primera «según el orden de la natu- raleza» y el otro en el orden de la socicdad...

No son menos relevantes, con todo, los caracteres manifiestamente positivos de la pitie. Su utilidad - -contribuye a la conservación mutua de toda la especie»- es tal que, sin ella en apoyo de la razón, los hombres serian monstruos y uhace ya mucho tiempo que no existiría el género humano». Pero, más allá de sus benéficos efectos preventivos, la entraña virtuosa de la compasión se pone de relieve en su caráctor de radicalidad en la lista de sentimientos morales. A juicio de Rousseau, ade esta sola cualidad dimanan todas las virtudes sociales», que no serían en el fondo sino la piedad aplicada a objetos particulares. Aquel enunciado negativo de la piedad ocultaba, por tanto, una naturaleza eminentemente positiva; esa repugnancia a ver sufrir a su semejante deja paso a la «repugnancia que todo hombre expcrimenta en hacer el mal, y ésta por fin al deseo de hacer el bien: «Pues desear que alguien no sufra, ino es lo mismo que desear que sea feliz? » $Y$ se añadirá todavía, para resaltar su ventaja respecto de los demás sentimientos o virtudes, su universalidad. Ni las costumbres más depravadas logran cxtinguirla ni está ausente del corazón de los pcores. «Finalmente, a pesar de uno mismo, tenemos compasión de los infortunados; cuando somos testigos de su mal, sufrimos. Ni los más perversos podrian desprenderse por completo de esta propensión, a menudo los pone en contradicción consigo mismos» ( $E, 389)$. La piedad es universal por ser irresistible.

Pero todos estos rasgos proceden de -y se afianzan en- la nota más decisiva de la piedad: su naturalidad, es decir, su prerreflexividad. «Tal es el puro impulso de la naturaleza, antcrior a toda reflexion.» Tan natural es la piedad, dirá el ginebrino, que hasta los animales en ocasiones la experimentan. De tal manera precede en el hombre al uso de toda reflexión, que 
hubo de ser mucho más viva en el hombre salvaje que en el civilizado. Si es la razón la que engendra el amor propio y la reflexión la que lo fortifica, entonces la filosofía fuerza al hombre a aislarse en sî mismo, y el filosofo, el hombre cultivado en general, será el individuo menos piadoso. Y ello a tal punto que, en otro lugar, Rousseau casi se atreve provocativamente a asegurar «que el estado de reflexión es un estado contra natura y que el hombre que medita es un animal depravado $\Rightarrow(D D$, $156)$.

\section{La piedad, icontagio afectivo?}

De haberse detenido aquí la propia meditación de Rousseau, su doctrina acerca de la piedad hubiera quedado marcada por una notable ambiguiedad. Pues lo mismo que sustenta sus innegables propiedades como un sentimiento benéfico, radical y universal, a saber, su naturalidad, eso mismo lo rebaja también a la altura del animal. Cuanto más se acentúc su incompatibilidad (o su distancia) con la reflexión, tanto más se confina a la compasión en los límites del mero sentimiento, $y$ de un sentimiento - por otra parte- tanto menos verdadero y firme cuando menos primitivo. Otorgar a la piedad la categoria de avirtud naturals parece, pues, incurrir en una gruesa incoherencia. No es la dotación de esta facultad la que separa al hombre del animal; al contrario, la pitié se revela como instinto común a todos ellos. Lo probaría esa involuntariedad que incita al piadoso, como se ha dicho, a compadecerse a pesar de si mismo. Pero entonces este afecto innato, más que una «disposición conveniente a unos seres tan débiles como nosotros", prueba ser ante todo un reflejo inmediato de nuestra propia debilidad.

De nada vale que, mediante una finta imposible, Rousseau reniegue en el Emilio de la tesis de su Discurso sobre la des- igualdad: a saber, que la piedad - por ser una cierta repugnancia- sea ella misma una clase de sufrimiento. Afirmar, por el contrario, que upara compadecer el mal de otro hay que conocerlo, sin duda, pero no hay que sentirlo" ( $E, \mathrm{IV}, 307)$, resulta absurdo. Si bastara el conocimiento de esa desgracia, la malicia merecería el nombre de compasión, y tanto el científico del dolor humano como el avezado torturador pasarian por piadosos. Cierto es que «sólo sufrimos cuando juzgamos que él sufre», pero el solo juicio del dolor ajeno no implica el compadecerlo y tanto puede engendrat la pura indiferencia como la sevicia más refinada. La compasión es un cierto pesar; por tanto, no sólo un cierto saber, sino también un cierto sufrir.

Pero sólo se sufre en uno mismo, y carece de sentido sostener (como repetirá Schopenhauer) que "no es en nosotros, es en él donde sufrimos* $(E, \mathrm{IV}, 298)$. Es verdad que «mientras uno sufre, no se compadece más que de sí mismon (ibid., 307), si por tal se entiende que un cierto estar libre de pena resulta condición necesaria de la piedad hacia la ajena. En modo alguno puede, empero, significar que haya que borrar del piadoso el propio pesar que le viene de imaginar el del otro. A fin de dilucidar ese movimiento de transporte imaginario que está a la base de la piedad, bastaría con decir que sufrimos por el dolor del otro, pero no -evidentemente- el mismo dolor que el otro. Claro que conocemos su dolor como suyo y no como nuestro, pero, para conocerlo así, necesitamos imaginar cuál seria el nuestro en caso de que nos afectara aquel mal u otro equivalente. Aquel error del ginebrino procedía seguramente de su voluntad de deshacer ese malentendido, por el cual se concibe la piedad como una especie de fusión estricta entre su sujeto y su objeto, de modo que, para salvaguardar la diferencia entre su agente y su paciente, hubo de negar el sufrimiento del uno y reservarlo 
en exclusiva al otro. Pero, al hacerlo así, al privarle de su componente de sufrimiento propio, la compasión queda en buena parte desnaturalizada. Al fin y al cabo, ino se ha dicho que ues por no sufrir por lo que no quiero que sufra...)? ( $E, \mathrm{IV}, 315$, n. 4).

Así las cosas, y mirada únicamente en tanto que sentimiento (segün una distinción que más tarde se verá), no puede sostenerse que nuestro pensador pasara por alto los riesgos que acechan a la piedad. Bien al contrario, el autor de La Nouvelle Heloïse nos previene contra ellos a cada paso. Su potencia enternecedora, el exceso de sensibilidad que despierta, logran desarmar a Julie de sus más firmes propósitos (III, 18, pp. 256-258) y le obligan a confesar que «c'est la pitié qui me perdit» $(1,29$, p. 59). Si uno es sabio $(1,11$, p. 27), hay que desconfiar más bien de una pasión que, en su pereza habitual, se contenta con contemplar el mal ajeno (V, 2, pp. 401-402) $y$, cuando es activa, incurre cn la injusticia de atender a las desgracias próximas y olvidat las lejanas (II, 21, p. 198)... Este Jean-Jacques, que no pierde ocasión de dejar constancia una y otra vez en sus Confesiones de su natural piadoso ${ }^{2}$, al final de su vida reconoce de sí mismo: «Siempre demasiado afectado por objetos sensibles y sobre todo por los que llevan signos de placer o de pena, de benevolencia o de aversión, me dejo arrastrar por estas impresiones exteriores sin poder sustraerme nunca a ellas sino con la huida ${ }^{\prime}$ ( $E P S$, 9." paseo; las cursivas son mías).

Lo que aquí se dice de la piedad russoniana vale también para esa simpatía que los moralistas ingleses de su tiempo elevan a sentimicnto moral universal. Una y otra serían, en definitiva, muestras de la tendencia propia de la naturaleza humana (pero también animal) a una comunicación inmediata de las pasiones, tal como ya fue descrita por el poeta latino: «así como el rostro humano sonrie a quienes le sonrien, así también llora a la vista de los que lloran.... ${ }^{3}$. Pero, si éste fuera su mecanismo desencadenante, la piedad vendría a ser una emoción cuyo automatismo, espontaneidad e inmediatez ante su particular estímulo en nada le enalteceria respecto de las demás pasiones. $Y$, no siendo libre $y$ voluntaria, sino impremeditada y forzosa, mal se ve que pueda legítimamentc elevarse a virtud. Habría que encuadrarla más bien entre los efectos de una blanda sensiblería, porque la compasión no sería más que un producto del contagio afectivo.

Exhibida sin más en su carácter natural e inmediato, éste es uno de los flancos más vulnerables que la piedad ofrece a la crítica de quienes antes y despuếs la han juzgado como un síntoma de debilidad. Para Séneca, así como «son ojos débiles los que lagtimean ante las lágrimas de otros», tan enfermedad es la compasión (misericordia) como la risa que provoca la risa ajena o el irreprimible bostezo suscitado por la visión de otro bostezo cualquiera ${ }^{4}$. Al asentar el sentimiento de simpatía como deber, que entonces se convierte en humanitas, Kant distingue la humanidad que nace de la facultad o voluntad de comunicarse entre sí los sentimientos (humanitas practica) y aquella otra fundada «simplemente en la receptividad para el sentimiento común de alegría o de dolor ( $h u$ manitas aestetica), Y mientras la primera es libre y procede de la razón práctica, la segunda «no es libre (communio sentiendi illiberalis) y puede llamarse contagio (como el del calor o las enfermedades contagiosas) o también afección compasiva (Mitleidenschaft): porque se propaga de un modo natural entre hombres que viven juntos ${ }^{5}$. Éste es también uno más de los numerosos reproches que Nietzsche prodiga contra la piedad: «La compasión no se refiere a las máximas, sino a los afectos; es patológica. El dolor ajeno nos contagia, la compasión es un contagio" ". 
Más en particular, el contagio a que se reduce la compasión tendría lugar a travess de ese mecanismo o propiedad de la naturaleza que es la imitación de los afectos. La piedad seria, entonces, un mero sentimiento mimćtico. Imaginar que un ser semejante a nosotros experimenta algún afecto provoca en nosotros, según Spinoza, un afecto similar. Esta imitación de los afcctos, "cuando se refiere a la tristeza, se llama conmiseración" ?. Y si preguntamos todavía por la raíz última de tan peculiar mecanismo natural, de nuevo Nietzsche nos responde que esa imitación ha sido una pauta adquirida a lo largo de milenios por el animal humano a fin de conjurar sus propios temores. Siendo el hombre la criatura más tímida de todas y percibiendo un peligro en cuanto le rodeaba, «imitaba los rasgos y la actitud que veía ante sí, y sacaba una conclusión sobre las intenciones buenas o malas que pudiera haber tras aquellos rasgos y aquella actitud ${ }^{8}$. De aquel temeroso esfuerzo por reproducir en uno mismo los scntimientos de los demás provienen $-y$ sobreviven- en nosotros la simpatía y la piedad...

\section{La piedad perfectible}

Pero devolvamos la palabra a Rousseau, cuya completa doctrina de la piedad tal vez permita anular estas objeciones. Será el momento de referirse a esa cualidad que constituye la diferencia específica del hombre respecto del animal: la facultad de perfeccionarse, «facultad que, con ayuda de las circunstancias, desarrolla sucesivamente todas las demás, y reside en nosotros tanto en la especie como en el individuow (DD, 159; n. X, 246). Privado del instinto que rige a los bichos, el hombre suple esa carencia mediante su libertad, que no es sino otro nombre de su ilimitada perfectibilidad. El ser humano es un agente libre porque es capaz de acceder o de resistir a las órdenes de la naturaleza y de alcanzar conciencia de ello; y en eso mismo radica su carácter perfectible. Así que, en tanto que el animal -individual o específicamente-, por ser perfecto, es casi desde un principio lo que será siempre, el hombre (por naturaleza inacabado, indeterminado) puede llegar a ser lo que elija. Oue no nos confundan las palabras: esa facultad de querer, lo mismo le permite seguir la orientación marcada en su naturaleza que contradecirla, tanto le capacita para encumbrarse a las mayores cimas de la razón como le convierte en sel único que cstá cxpucsto a volverse imbécil» o le induce a caer «más bajo que el animal mismo» $(D D, 160)$. La perfectibilidad, en suma, es la que - con el tiempo- hace despertar en el hombre sus conocimientos y sus errores, sus vicios y sus virtudes.

$O$, lo que es igual, csta propicdad natural humana (en realidad, la estrictamente humana) equivale a su capacidad de desarrollar en múltiples sentidos las demás propiedades del hombre. Con ella viene sin más a decirse que sus cualidades naturales son cualidades potenciales o que el hombre es un ser en potencia. Pero entonces resulta que el ejercicio de aquella perfectibilidad, esto es, la humanidad en acto, corresponde tan sólo al estado civil o social del hombre, y no a su estado de naturaleza. Lo que el ser humano virtualmente -0 sca, naturalmente- es sólo se plasma, para bien o para mal, en su historia, no en su origen; no se manifiesta en su aislamiento, sino en su sociedad. Rousseau cree haber mostrado que ala perfectibilidad, las virtudes sociales y demás facultades que el hombre natural había recibido en potencia no podían nunca desarrollarse por sí solas, que para ser necesitaban el concurso fortuito de varias causas ajenas que podian no nacer jamás y $\sin$ las cuales el hombre habría permanecido eternamente en su condición primitiva...» (DD, 179). $Y$ es que el hombre salvaje, en efecto, en 
poco se diferencia aún de los brutos. Igual que sus funciones son puramente animales, sus pasiones se mantienen en la misma simplicidad que su entendimiento y sus deseos no rebasan el nivel de sus meras necesidades físicas. Tendrá, por ejemplo, conciencia de dolor, pero no de la muerte, pues «el conocimiento de la muerte y sus terrores [es] una de las primeras adquisiciones que hizo el hombre al apartarse de la condición animal» $(D D, 161)$.

Como una de esas pasiones naturales, la piedad será asimismo una pasión perfectible. Ni está dada de una vez para siempre ni, por tanto, se agota en los modos que adopte en el hipotético estado de naturaleza. Al contrario, este sentimiento, cuyo abandono o cultivo puede históricamente plasmarse en su desprecio o en su conversión en virtud, está más bien ausente de hecho entre los hombres primitivos. Estos, diseminados por la superticie de la tierra, sin idea de fraternidad alguna que los uniera, recíprocamente temerosos por ignorantes, debian de ofrecer el aspecto de animales feroces. \&Las afecciones sociales sólo se desarrollan en nosotros por medio de la inteligencia. La piedad, aunque natural al corazón humano, permanecería eternamente inactiva si la imaginación no la pusiera en movimiento. ¿Cómo nos dejamos conmover por la piedad? Trasladándonos fuera de nosotros mismos, identificándonos con el ser sufriente (...). IImaginad cuántos conocimientos adquiridos supone esta transferencia! ¿Cómo imaginar males que desconozco? ¿Cómo sufriría viendo sufrir a otro si no sé que sufre, si ignoro lo que hay de común entre él y yo? El que jamás ha reflexionado no puede ser ni clemente, ni justo, ni piadoso, como tampoco puede ser malo y vengativo. El que nada imagina sólo se siente a sî mismo, está solo en medio del género humanom $(O L, 92)^{9}$.

Con relación a su doctrina precedente, Rousseau se impone aquí dos severas correcciones. De una parte, que el estado de reflexión sería un estado contra matura sólo si csta naturaleza humana fuera una entidad tcrminada, pero del todo afín a ella si la perfectibilidad resulta la nota más especifica de aquella naturaleza. A menos que el reflexivo Jean-Jacques admitiese ser por ello mismo un degenerado, el hombre no es un animal depravado por el hecho de meditar. Siendo naturalmente perfectibles, el individuo y la especie humana son, desde luego, depravables, pero también susceptibles de alcanzar la virtud. $\mathrm{Y}$ el ejercicio de la reflexión aparece como requisito necesario, aunque no suficicnte, de lo uno y de lo otro... Pero, de otra parte, más claro aún resulta que la compasión no brota como un afecto propio de las fases primitivas de la humanidad, donde sólo hay dispersión de los individuos ( $y$, con ella, inmensa pobreza de sus deseos y necesidades), sino más bien de su estadio civilizado, en el que el vínculo social ( $y$ el desarrollo consiguiente de la pasiones) exige su mutua comparación. En tanto que productos de este mecanismo asociativo, la reflexión - la imaginación-y y la piedad se rcquieren la una a la otra, «La reflexión nace de las ideas comparadas y es la pluralidad de las ideas la que lleva a buscar sus conexiones. El que sólo ve un objeto no tiene ninguna comparación que hacer" (ibid.). "Comparer c'est jugern, dirá Rousseau. Faltos, pues, de término humano con el que medirse, ignorantes de cualquier otro y de sus males y del hombre en general, los primeros hombres son tan impotentes para la reflexión como para la piedad. Mientras ésta sólo trate de mitigar el celo de su propia autoconservación, apenas podrá ejercerse hasta que el individuo no tenga ocasión de ponerse en el lugar del otro. A fin de cuentas, la misma instancia social comparativa que hace posible el amor propio - la competencia, la vanidad-- despierta también la piedad. 
De modo que atribuir un carácter natural a la piedad no implica considerar al hombre, como individuo o como especie, necesariamente y siempre piadoso. La «vejez $u$ otros accidentes" pueden hacer perder a los individuos lo que su perfectibilidad les habia permitido adquirir. Si damos crédito al testimonio de un desengañado Rousseau, su propio talante compasivo se debilitó con el tiempo: más proclive al desprecio que al odio, nos cuenta que se habría compadecido de mejor grado de un perro sufriente que de aquellos hombres a quienes ya no lograba ver como semejantes (EPS, 97-98, 161-162). En suma, la naturalidad de la compasión no clausura sus virtualidades de decrecer o, al contrario, de expandirse en múltiples modos.

Por cllo mismo tampoco ese carácter natural denota que el hombre sea animal. mente piadoso; 0 , mejor dicho, que al ser humano le baste conformarse con aquella piedad de la que también el bruto sería capaz. La compasión propiamente humana - puesto que es perfectible - no se agota en aquella "repugnancia innata a ver sufrir a su semejante», que será tan sólo su grado más bajo e incipiente. La piedad que el hombre desarrollado debe conquistar supera el mero contagio afectivo del que tal vez ciertos animales dan muestras. Y es que la prerreflexividad de la compasión no cquivale, ni mucho menos, a su irreflexividad. Lo que la naturaleza pone en el hombre antes de toda reflexión es tarea humana perfeccionarlo mediante la reflexión. Si ésta puede aislar al hombre y volver al filosofo insensible hacia la desgracia ajena, ese mismo ejercicio intelectual puede también agudizar su sensibilidad. Rousseau, que no predica un imposible regreso de la Humanidad al estado de naturaleza, tampoco reclama una vuelta a la bruta piedad natural. Los sentimientos humanos son ya, como humanos, afectos socializados $y$ en alguna medida espiritua- lizados, filtrados tanto por la sociedad como por las ideas. Igual que el entendimiento del hombre debe mucho a las pasiones, éstas «recíprocamente le deben mucho a $\mathrm{l}($ (..) y su progreso se debe a nuestros conocimientos» $(D D, 160)$.

No se piense, con todo, que Rousseau haya olvidado ni por un momento cuál sea el sustrato último del que emerge, como cualquier otra pasión, la piedad. "La fuente de nuestras pasiones, el origen y el principio de todas las demás, la única que nace con el hombre y nunca le abandona mientras vive, es el amor de sí: pasión primitiva, innata, anterior a cualquier otra y de la que todas las demás no son en cierto modo más que modificaciones) $(E, 283)$. He ahí la precedencia absoluta, la irrebasabilidad de un principio tan primario como que sin él la mera subsistencia sería imposible; y tan expansivo, que si mueve a que nos amemos para conservarnos, «por una consecuencia inmediata del mismo sentimiento, amamos lo que nos conserva». No es, pues, la pitié una instancia diferente y contrapuesta al amour de soi, como parecia desprenderse de su segundo Discurso. La piedad resulta más bien un modo particular del amor de sí, el modo que éste adopta en la relación con los otros a fín de no desbocarse en inmoderado amor propio.

Pero este amor de sí es todo menos una pasión simple. Al contrario, «consta de dos principios, el ser inteligente y el ser sensible, cuyo bienestar no es el mismo» ( $C h B$, 540). Mientras el apetito de los sentidos sólo busca el bien del cuerpo, el afán del alma - al que llamamos conciencia- se confunde con el amor al orden. Ahora bien, como la conciencia sólo se desarrolla $y$ actúa con las luces del hombre, y éstas se encienden cuando los individuos empiezan a poner los ojos en sus semejantes, no hay verdadero amor de sí hasta tanto no se afianzan las relaciones sociales. Sólo éstas (es decir, en un estadio avanzado de la evolución de la especie y del individuo) 
ponen, al tiempo que las condiciones de la aparición del amor propío, las condiciones del ejercicio social del amor de sí. La piedad puede surgir cuando hay yoes relativos los unos a los otros, esto es, cuando la inevitable comparación del individuo con sus congéneres le fuerza a interrogarse sobre el puesto que ocupa entre ellos $(E$, 315 y 327): o, para decir lo mismo, tanto puede brotar del amor de sí como ser agostada por el amor propio. Siendo el amor de sí como tal «indiferente al bien y al mals, cada una de sus complejidades son otras tantas ocasiones de deslizarse hacia el mal. Rousseau lo expresa en fórmula precisa: «Se quiere siempre el bien propio, pero no siempre se sabe dónde está ese bien» (CS, II, 3).

Afirmemos, pues, sin reparo alguno la naturalidad de la compasión en la misma medida en que afirmamos su connaturalidad con el insoslayable amor de sí: * Cuando la fuerza de un alma expansiva me identifica con mi semejante y yo me siento, por así decir, en él, es por no suffir por lo que no quiero que sufra; me intereso en él por amor de mi, y la razón del precepto está en la naturaleza misma, que me inspira el deseo de mi bienestar en cualquier lugar en que me sienta existir» ( $E, 315$, n. 4). ¿Acaso cabe mayor reconocimiento de la presencia de ese desco de bien para uno a la base de la piedad para con otros...? Pero cso no basta para asegurar su debida perfectibilidad. Pues, al igual que una reflexión permanente habrá de depurar ese amor de sí para impedir que degenere, sólo una constante vigilancia sobre la piedad natural e inmediata podrá librarla de las torpezas espontáneas en que como simple sentimiento tiende a incurrir. Contra la siempre posible caída en el mero contagio afectivo, hay que aspirar a una piedad que sea prueba de fuerza y no de debilidad (a una «humanité sans faiblesse». E, 356), alcance un ámbito universal y se traduzca en una beneficencia activa.

\section{Pedagogía de la piedad}

Para Rousseau ese sentimiento es perfectible en la humanidad entera a lo largo de su historia, merced a causas hasta ahora fortuitas. En este punto, el mismo que desplegó los progresos de la desigualad entre los hombres para mostrar cómo es posible «volver malo a un ser socializándolo» ( $D D$, 179), habría suscrito sin dudarlo la doctrina más tardía de que los mecanismos cosificadores del mercado inhiben todo afecto de piedad en sus participantes ${ }^{10}$. Pero tambiên habria debido aceptar que las modernas sociedades democráticas, en tanto que animadas primordialmente por la pasión de la igualdad, fomentan como ninguna otra los sentimientos de piedad ${ }^{11}$...

Sea de ello lo que fuere, si el progreso de nuestras pasiones debe mucho a nuestro entendimiento, a un esfuerzo racional se debe asimismo el progreso de la piedad en el individuo. De ese empleo de la razón depende, primero, que la piedad natural ahonde como sentimiento $y$, después ( $y$ sobre todo), que el mero sentimiento deje paso a la virtud de la piedad. Aquellas circunstancias, aquel concurso fortuito de causas que favorecían la perfección de los rasgos diferenciales humanos, pueden procurarse de modo consciente. Buena parte del cuarto libro del Emilio está dedicada, en efecto, a trazar las lineas maestras de una pedagogia de la piedad. El discípulo, que ha comenzado a salir de sí mismo y a entablar relación con los demás, empieza también a sentir las primeras pasiones sociales: acaba de ingresar en el orden de la moralidad $(E, 293,315)$. Es el momento escogido por su preceptor -esto es, por Rousseau - para "poner orden y regla en las pasiones nacientes» $y$ «animar en él 
los primeros movimientos de la naturaleza» ( $E, 292$ y 303 ). Se adopta, pues, un método que, además de seguir «el orden $y$ el progreso de nuestros sentimientos y de nuestros conocimientos», logre que lo que en un principio aparecen como simples inclinaciones naturales se conviertan en «inclinaciones cultivadas» (penchants cultivès. $E, 304)$.

Pues bien, el punto de partida es la constatación de que la piedad viene a ser la primera forma de la relación humana. Puesto que no nos une a los otros tanto el sentimiento de sus placeres como el de sus pesares, si es la debilidad compartida y la común miseria lo que nos vincula, la compasión sería el modo más originario de nuestra sociabilidad. «Así nace la piedad, primer sentimiento relativo que afecta al corazón humano según el orden de la naturaleza» $(E, 295-296)$. Ese sentimiento, sin embargo, permanece latente a falta de ciertas condiciones que le azuzen a manifestarse y crecer. Y su requisito más inmediato, si es verdad que hay que comenzar por estudiar al hombre para juzgar a los hombres, es el conocimento de la naturaleza humana $(E, 322)$, ide dónde procede la eventual insensibilidad ante aquella miseria de la que todos participamos como no sea de su ignorancia? $(E, 303)$. Arrancadas sus variadas máscaras individuales, el estudio de lo más inseparable de la naturaleza humana, de lo que mejor expresa a la humanidad, nos depara una lección elemental: «Todos han nacido desnudos y pobres, todos sometidos a las miserias de la vida (...), a los dolores de toda especie; finalmente, todos están condenados a la muerte. He ahí lo que es realmente el hombre; he ahí eso de que ningún mortal está exento» $(E, 296)$. Hay que conocer a los hombres «tal como son», y no para odiarlos, sino para compadecerlos. Éste es, «en mi opinión, el sentimiento mejor entendido que el hombre puede tener sobrc su especie.... $(E, 317)$.
Claro que no es la mera idea de una humanidad doliente la capaz de excitar la compasión, sino el conocimiento particular de los sufrimientos humanos lo que -precisamente por padecerlos por igual- convierte a los hombres en nuestros semejantes y nos impulsa a compadecerlos. Mientras nos sean extraños, mientras la desgracia de su suerte no nos evoque lo probable de nuestra propia desgracia, la piedad natural queda en suspenso. "Para volverse sensible y compasivo es preciso que el niño sepa que hay seres semejantes a êl, que sufren lo que él ha sufrido, que sienten los dolores que él ha sentido y otros de los que debe tener idea porque también puede sentirlos» $(E, 298$ y 300$)$. Sin exceso [porque no es bucno «pasearlo de enfermo en enfermo, dc hospital en hospital» ( $E_{\text {s }}$ $310)$ ], para no endurecerie, pero hay que mostrar al alumno el espectáculo de las penalidades humanas. Sólo entonces se hace prácticamente posible ese movimiento que a uno le transporta fuera de sí mismo y le pone en el lugar del otro.

Pero es en este punto preciso donde la línea educativa de la piedad se bifurca. Aquí - aun con ciertas dificultades y se diría que a veces sin la conciencia expresa de Rousseau - asoman dos caminos conducentes a otros tantos modos o grados de compasión: la piedad como sentimiento cultivado, el uno, y la piedad ya como virtud, el otro. Su diferencia no radica sólo en el distinto motor que las anima, sino en el distinto alcance de los males que contempla, así como en el diverso discernimiento, cuantitativo y cualitativo, de los objetos a los que se aplican. Si la emoción piadosa brota de la comparación inmediata con el otro, la virtud de la piedad requiere la mediación de un profundo conocimiento del hombre. Mientras la primera se confunde con un contagio afectivo, la segunda encuentra en ese contagio su mayor obstáculo y se esfuerza en depurar al máximo a la compasión de la sensibilidad de la que 
surgió y que todavía la acompaña. En un caso la piedad está aún teñida de amor propio, en el otro es ya hija legítima del amor de sí. Tal es la clave de la respuesta de Rousseau a quienes, por suponer a la piedad producto de un instito natural, la desdeñan. En suma, hay otra forma de piedad mucho más digna que la contagiosa y mimética.

\section{La piedad como sentimiento}

El sentimiento de piedad, en efecto, se acomoda fácilmente a las máximas que a su propósito enumera nuestro autor. Dice la primera que «no es propio del corazón humano ponerse en el lugar de personas que son más felices que nosotros, sino sólo de aquellas que son más de compadecer» $(E, 298)$. Pero hay motivos para sospechar de una emoción tan cercana a la envidia y al resentimiento, de un afecto tan pobre que su protagonista seria capaz de compadecerse del mal de otro, pero en modo alguno de congratularse de su bien. En el reconocimiento de esa impotencia, la mera compasión sentimental viene a confesar su propio carácter miserable. Tampoco la segunda máxima acerca de la piedad, según la cual nunca se compadecen en los demás sino los males de los que no nos creemos libres $(E, 299)$, la eleva por encima de la sensibilidad. Pues una creencia infundada en su bienestar presente, o en la improbabilidad de su desgracia futura, puede deslucir por completo el sentimiento del piadoso. Sería de hecho una piedad errónea o contradictoria que, aderezada con dosis variables de vanidad y superioridad, traería consigo el desprecio hacia el compadecido. Tal ocurre con la compasión dictada por el amor propio, ese afecto que nos lleva a compararnos y a encumbrarnos sobre cualquier semejante. «Al considerar su rango en la especie humana y verse tan felizmente situado en ella, Emilio (...) se dirá: soy sensato y los hombres son locos. Compadeciéndolos los despreciará, felicitándolos se estimará más; $y$, sintiéndose más afortunado que ellos, se creerá más digno de serlo. He ahí el error más de temer por ser el más difícil de destruir...» (E, 329).

¿Acaso no es este último un riesgo seguro que corre el piadoso, si resulta inevitable que su sentimiento se acompañe, ya que no del desprecio hacia su objeto, sí al menos de una conciencia satisfecha nada lejana de su propia sobreestímación? "La piedad es dulce, porque al ponernos en el lugar del que sufre sentimos el placer, sin embargo, de no sufrir como él» $(E$, 296). Algunos ${ }^{12}$ han visto en ello el papel irónico y hasta paradójico que en el pensamiento de Rousseau juega la piedad, un sentimiento que parece participar a un tiempo de los rasgos del amor de sí y del amor propio. Pero la paradoja se desvanece en cuanto se consideran los caracteres de instantaneidad y provisionalidad (o sea, las notas contrarias a las que tendria si fuera un producto de Ia reflexión) que como sentimiento le corresponden. Resul. ta explicable entonces que, sicndo el primer espectáculo que sorprende a Emilio un objeto de tristeza, el primer repliegue sobre sí mismo venga con un sentimiento de placer..., pero nada sabemos de los siguientes. Así como tampoco ha de extranar que «disfrute» a la vez de la compasión para con los males ajenos y -con tal de suponerla sólo momentánea- de la felicidad presente que lo exime de ellos. Por lo mismo, en fin, ese "estado de fuerza" por el que la piedad nos permite dispensar al otro la parte sobrante de nuestra atención viene definida en términos sensibles; desde la razón que aún ha de imponerse, en cambio, aquel sentimiento es más bien prueba de una cierta debilidad... Podría confirmarlo la última de las máximas, para la que la piedad del mal ajeno se mide por el sentimiento que atribuimos a quie- 
nes lo sufren $(E, 301)$. Pues esa regla certifica que nuestra respuesta afectiva a la desgracia del otro no depende tanto de la objetividad de su desdicha misma, sino del albur de nuestro propio afecto hacia quien la padece y, así, del sentimiento que en la imaginación le prestemos como suyo. En último término, si el sentimiento ajeno sólo nos es accesible a través del propio y de sus imprevistas variaciones, raro sería que la compasión de ese mal fuera en verdad congruente con la naturaleza misma del mal. Cuando sólo la sensibilidad está en juego, lo más probable es una piedad meramente aproximada ( $y$, por eso, inapropiada) a su objeto.

De ahí que este género de compasión, por el hecho de desencadenarse ante los males más aparentes, sea entre los hombres el más temprano y común. Su dependencia respecto de las impresiones sensibles limita la extensión de los objetos compadecibles al «aparato de las operaciones dolorosas" y, sólo más tarde, a la idea de la muerte, pero le pasan desapercibidas las penas morales y las aflicciones más sutiles $(F, 303-304)$. De modo correspondiente, en la tipología de piadosos predomina ese individuo para el que la amplitud del círculo al que alcanza su compasión es asimismo muy reducida: «esa sensibilidad se limitará primero a sus semejantes, y sus semejantes no serán para él desconocidos, sino aquellos con los que mantiene relaciones, aquellos que el hábito le ha hecho queridos y necesarios» $(E, 313)$. A decir verdad, el rigor lógico obligaria a incluir como nota de esta piedad más o menos próxima a la sensiblería la propensión a hacer distingos entre sus posibles destinatarios. Arrastrado por sus primeras impresiones, el piadoso sólo dedicaría su compasión a quien a sus ojos la merece, es decir, al pobre o al bueno, pero no al rico y al malvado. De hecho, más que piedad, «es grandísima crueldad hacia los hombres la piedad por los malvados» $(E, 340)$. Pero aquí incurre nuestro autor en una incoherencia que sólo se resuelve si se desplaza el análisis hacia la otra forma de piedad.

\section{La virtud de la piedad}

Porque hay, a juicio de Rousseau, otra especie de compasión que sc libra de las servidumbres y limitaciones de la sensibilidad y asciende al grado de virtud. Este es el estadio superior de su desarrollo en el individuo (y en la Humanidad), tal es la meta a que aspira una pedagogía de la piedad. $Y$ esa piedad que es ya virtud sólo puede conquistarse merced a la reflexión, mediante un ejercicio permanente de la razón asentado en el conocimiento de la naturaleza humana y de los hombres singulares. La piedad es entemecimiento $y$ reflexión, 0 , mejor aún, un enternecimicnto que para ser realmente valioso debe nacer de la reflexión. «No es tanto lo que [el verdadero compasivo] ve como su vuelta sobre lo que ha visto lo que determina el juicio que sobre ello tiene; y la duradera impresión que recibe de un hecho le viene menos del hecho mismo que del punto de vista desde el que se le induce a recordarlo» $(E, 310)$. Si sólo fucra ciega y espontânea reacción ante el mal contemplado, la compasión sería ciertamente un contagio en el orden de los sentimientos. Pero si admitimos con Rousseau que, tan pronto como el hombre comienza a pensar «ya no cesa» ( $E, 342$ ), entonces no habrá emoción que se produzca al margen del pensamiento. Si «toda sabiduría humana en el uso de las pasiones» se resume en ordenar los afectos del alma según las verdaderas relaciones del hombre, entonces no hay pasión que merezca llamarse en puridad humana si no cae bajo el poder -co. mo individuo o como especie- del hombre $(E, 293)$. En definitiva, la sabiduría acerca de los sentimientos consiste en que el hombre sea su señor, es decir, sea wdueño 
de dirigir su imaginación hacia tal o cual objeto, o de darle tal o cual hảbito» (la cursiva es mía). La piedad permanece como pasión (o sea, como contagio) cuando su aparente sujeto no es tal, sino su objeto. La piedad se convierte por fin en virtud cuando su sujeto la domina, cuando es una pasión libre.

Desde esta especial exigencia, la compasión gana en cuanto a calidad y cantidad de los males susceptibles de desencadenarla y, con ello, en el número de seres humanos dignos de recibirla. Por guardar el paralclismo con los rasgos propios de su modo anterior, la virtud de la piedad ya no se limita a ponerse tan sólo en el lugar del sufriente... por aquello de que la identificación con el más venturoso sería causa segura de envidia. Esa piedad no puede estar reñida con la simpatía o complacencia hacia la felicidad ajena. Ese piadoso es incluso capaz de apiadarse del que se muestra como feliz por lo que inevitablemente tiene de infeliz. "IAl rico o al grandel a veces se le ama on sus desgracias, pero mientras prospera no hay más amigo verdadero que aquel que no es víctima de las apariencias y que lo compadece, más que lo envidia, a pesar de su prosperidad» $(E, 299)$. Y es que, por otra parte, no hay mal del otro del que no podamos apiadarnos si sabemos que no hay mal del que nosotros mismos estemos libres. Cualquier presunción de estar definitivamente al abrigo de las desgracias de la condición humana sería ridícula, toda atribución de superioridad del compasivo ante el desdichado está fuera de lugar. Ni siquiera los hombres más grandes se engañan sobre su estado, sino que su misma conciencia les inclina a la compasión: «Cuanta más [superioridad] tienen, más saben todo Io que les falta. Están menos envanecidos de su elevación sobre nosotros que humillados por el sentimiento de su miseria» ( $E$, 329-330).
Por cso, a difcrencia del sentimiento que se despierta ante los gritos de dolor y las desgracias patentes, pero que apenas llega más allá, a la piedad virtuosa -menos común, más tardía - le afectan también las pesadumbres más íntimas $y$ soterradas $(E, 304) . Y$, sobre todo, este género de piedad no hace acepción entre sus objetos posibles; su tendencia irrefrenable es hacia la universalidad sin reservas. El piadoso por afección reducía su sentimiento al círculo siempre exiguo de sus conocidos. «Sólo después de haber cultivado su carácter de mil maneras, después de muchas reflexiones sobre sus propios sentimientos y sobre lo que observe en los demás (la cursiva es mía), podrá llegar a generalizar sus nociones individuales bajo la idea abstracta de humanidad y unir a sus afecciones particulares las que puedan identificarle con su especie» $(E, 313)$.

Ya no se trata de aquella piedad que, en tanto que dotados de una sensibilidad común, reclamaba Rousseau a los hombres para los sufrimientos de los animales; ahora se les demanda una piedad más alta, que sólo puede dirigirse a los de su especie y a la especie humana como totalidad. Tampoco hablamos de aquel grado inferior de compasión que, por basarse tan sólo cn el sentimiento inmediato, daba muestras de estar afectado de alguna debilidad. Estamos más bien en el paso del sentimiento a la virtud y ante el movimiento de universalización que lo hace efectivo: «Extendamos ol amor propio (léase aquí "amor de si", pues ése es su sentido preciso, A. A.) a los demás seres, lo transformaremos en virtud, y no hay corazón humano en el que esa virtud no tenga su raíz (...). Para impedir que la piedad degenere en debilidad es menester, pues, generalizarla y extenderla a todo el género humano. Entonces no nos entregamos a clla sino cuando está de acuerdo con la justicia, porque, de todas las virtudes, la justicia es la que más concurre al bien 
común de los hombres. Por razón y por amor a nosotros mismos, hay que tener măs piedad de nuestra especie que de nuestro prójimo» $(E, 339-340)$. De ser así, la compasión por el prójimo debe subordinarse a la compasión por la humanidad entera; o, lo que es igual, esa virtud sólo prueba fehacientemente su virtus cuando abarca a la especie, y no se limita (por debilidad sensible) al individuo. La piedad llega hasta donde alcanza la justicia, y es virtud sólo en tanto en cuanto concuerda con ella.

A lo que sólo faltaría añadir, por último, que no hay virtud en la pitié mientras ésta no sea activa, hasta que no culmine en la efectiva beneficencia. Si al sentimiento piadoso le basta con su mera autocomplacencia, en su grado de virtud la piedad deja de ser tan sólo compasiva y se entrega de lleno a la acción. Si el efecto compasivo se despierta por el espectáculo de la miscria (y ahí radica su esencial limitación), para la virtud de la piedad «c'est l'existente et non la vue des malheureux qui la toumente»; en tanto que el uno se satisface con ignorar la desgracia ajena que no ve, la otra sólo descansa cuando sabe con certeza que no hay tal desgracia a su alcance $(\mathrm{NH}$, $V, 2$,pp. 401-402). De ahí que esta piedad más elevada nada tenga en común con kesa piedad estéril y cruel que se contenta con compadecer los males que puede curar» (E, 337-338). Ya su estrecho parentesco con la justicia le induce a investigar, cuando son asequibles a la intervención humana, tanto las causas de los males que descubre como los medios para remediarlos. Pero, más allá de la tierna emoción compasiva y hasta del afán de justicia, es el deseo mismo de la felicidad ajena lo que mueve a la piedad cuando es virtud. Tal le ocurre a Emilio, a quien «la imagen de la felicidad lo lisonjea $y$, cuando puede contribuir a producirla, es un medio más para compartirla». Ya se dijo antes: lo que comenzaba como una repugnancia ante $\mathrm{cl}$ sufrimiento de un semejante acaba en el deseo comprometido de su felicidad.

\section{Piedad y justicia}

Así que babrá que discrepar de Rousseau en la exacta medida en que, en este punto, Rousseau discrepa consigo mismo. A primera vista, y según la anterior conclusión, el malvado está del todo excluido de los favores de la piedad y compadecerse de sus apuros sería un gesto de crueldad hacia sus víctimas. En esa incongruencia caen los que no distinguen entre quienes sufren males merecidos y quienes los sufren sin merecerlos, esos piadosos complacientes e inactivos que mantienen la convicción de que felicidad y desgracia se reparten a partes iguales entre pobres y ricos. ¿Cómo no repudiar tan burdo sofisma? aLas penas del rico no le vienen de su estado, sino sólo de él, que abusa de este estado. Aunque fuera más desventurado que el pobre mismo, no hay que compadecerle, porque sus males son todos obra suya, y sólo de él depende ser feliz» $(E, 302)$. Apiadarse de las tribulaciones del culpable, cualesquiera que sean, parece sin duda un agravio contra los inocentes que aquél ha dañado.

Sí, mas ino se estará estrechando en exceso la noción de mal para hacerla denotar tan sólo los males de naturaleza social, los engendrados por las relaciones humanas? Según eso, tno se recorta así la universalidad peculiar del objeto de la piedad como virtud?; $y$, con cllo, bacaso no se fucrza a la piedad a ser nada más - aunque no sea poco- que una piedad política? La respuesta es desde luego afirmativa, a tenor de textos sumamente clarificadores. «El hombre es el mismo cn todos los estados (...). Ante quien piensa (la cursiva es mia), todas las distinciones sociales desaparecen» $(E, 301)$. Por sangrantes que 
sean las desigualdades sociales que separan y enfrentan a los individuos, siempre serán menos dolorosas que los males emanados de la condición humana misma que los une. Mientras aquéllas pueden al menos ser combatidas y cn último término resultan superables, la férrea necesidad con que los últimos se imponen privan de toda esperanza a la empresa de erradicarlos. También los criminales, como sus víctimas, han de morir. La piedad social y política se mueve todavía en una lógica de lo particular, delimita unas preferencias y exclusiones para su ejercicio. La piedad a secas, como virtud, sólo es tal por ser universal: no cicrra los ojos a los males singulares, sino que percibe el mal encerrado tras la apariencia de los males singulares. De modo que esa compasión que ciertos hombres no merecerian como malvados se la ofreceremos porque son hombres.

Pero, a fin de cuentas, también se la debemos en su condición misma de malvados. Si la piedad virtuosa alcanza, por un lado, su carácter universal al cubrir con su manto incluso al próspero (pues tras su momentánea felicidad percibe su última y segura desventura), esa misma universalidad se manifiesta del otro lado cuando comprende asimismo al perverso. Éste paga sus males con su propio mal; un mal que, por pertenecer a la clase menos visible de las penas humanas, queda oculto a la mirada del amor propio y sólo resulta accesible a la verdadera piedad: «es nuestro propio interés el que nos hace odiar a los malvados; si no nos hicieran ningún mal, tendríamos para ellos más piedad que odio. El mal que nos hacen los malvados nos hace olvidar el que se hacen a sí mismos (...). Sentimos la ofensa y no vemos el castigo; las ventajas son aparentes; la pena es interior...» $(E, 328)$. La compasión que suscitan las victimas de sus fechorias, la indignación que alimenta cl clamor de justicia contra el autor de esos crimenes, en nada prohíben la cxigcncia de una última piedad para con el malvado.

¿Y cuáles son ese castigo y esa pena interior que estos individuos, en apariencia mấs libres de sufrimiento y más determinantes del sufrimiento ajeno, también sufren y por los que demandan piedad? Ante todo, su servidumbre, si es cierto que ésta es «el peor de los males». Tal es la idea que anima la conducta compasiva de Emilio, una vez que su piedad natural ha sido depurada por la reflexión: «Compadece a esos miserables reyes, esclavos de todo lo que les obedece; compadece a esos falsos sabios (..), a esos ricos necios (...), a esos voluptuosos de parada (...). Compadecería al cnemigo que le hiciese mal a él mismo, porque en sus maldades vería su miseria. Se diria: imponiéndose la necesidad de hacerme daño, este hombre ha hecho depender su suerte de la mía $(E$, 329).

Bien se ve, pese a ciertas tesis de tenor opuesto, que para Rousseau la piedad ni coincide con la justicia, ni es una forma de justicia, sino una virtud diferente de ella. En cierto sentido, la piedad es requisito imprescindible de la justicia: «Podrán [los hombres endurecidos] ser íntegros y justos, nunca clementes, generosos ni compasivos. Digo que podrán ser justos si es que puede serlo un hombre cuando no es misericordioso» $(E, 304)$. En otro, la piedad trasciende con mucho a la justicia, si el delincuente ha de ser compadecido en los males generales derivados de su condición humana y además en los propios de su carácter perverso. Una justicia despiadada es por principio sospechosa, pero la piedad, para ser tal, rcquiere ser injusta.

Dos protagonistas de La Nouvelle Heloise ejemplifican a la perfección la distancia entre ambas virtudes. Mientras Julie encarna la compasión, a su marido - Mr. De Wolmar - tan sólo le mueve la justicia: «Poco scnsible al placer y al dolor, sólo muy débilmente experimento ese senti- 
miento de interés y de humanidad que nos lleva a apropiarnos de las afecciones de otro. Si me duele ver sufrir a las gentes de bien, la piedad no entra aquí para nada, pues no tengo ninguna en ver sufrir a los malos. Mi único principio activo es el gusto natural por el orden..." (NH, IV, XI, p. 368). Ese amour de l'ordre, que sólo mostraría compasión (como en Aristóteles) hacia los males sufridos por quienes no los merecen, no rebasaría el plano de la justicia.

Se atisban entonces dos grados en la virtud de la piedad. De un lado, si ésta es «la raíz de todas las virtudes sociales», también to será de esa virtud social culminante que es la justicia; la compasión conduce a la justicia, y queda subordinada a ella, como su auxiliar necesario. Pero, de otro lado, la piedad lanza su mirada más allá de la justicia; si ésta viene a ser la piedad hacia la especie, y puede por ello desentenderse de las desgracias singulares o incluso llegar a causarlas, la piedad en su grado más sublime se vuelve de nuevo hacia los males de todos los individuos sin dejar ni uno.

\section{NOTAS}

${ }^{1}$ La Nouvelle Heloüse (NH), Paris, Garnier-Flam marion, 1967, V, 2, p. 407. Las demás obtas de Rousseau se citarán por estas siglas y ediciones: Discurso sobre el origen y fundamento de la desigualdad entre los hombres (DD), Contrato Sochal (CS). Carto a Cmisrophe de Beaumont (ChB), todas ellas en Escritos de combate, Madrid, Alfaguara, 1979; Emalio (E), Midrid, Alianza, 1990; Essai surl'ongine des langues (OL), París, Gallimard, 1990, Ensoñaciones de un paseante solitario (EPS), Madrid, Alianza, 2. $1,1988$.

Confesiones, Madrid, Tebas, 1974 (París. Galli mard, 2. vols., 1973). Entre otros lugares, vếase caps. $V$, $216(\mathrm{I}, 275)$; VII, 321 (II, 71); VIII, 349 (II, 104); IX, 402 y ss. (II, 165); IX, 413 (II, 179); IX. 435 (II, 204); IX, $446(I I, 212) ;$ IX, 458 (II, 232-233); X, 499 (II, 281); XI, 536 (II, 324); XII, $600($ II, 402); XII, 615 (II, 419)

3oracio, Ars poerica, pp. 101-102.

* Sobre la clemencia, Madrid, Tecnos, 11, 6, 4, 1988. Cfr también II, 4-5.
"Kant, Metafisica de las costumbres, Segunda parte, 34, Madrid, Tecnos, 1989, pp. 327-328.

- La voluntad de dontinic, II, núm. 368, en Obras Completos, Madrid, M. Aguilar Editor, t. VIIr, 1932 , pp. 210-211.

Etica, III, XXVII, pp. 208-209 (ed. cit.). Cfr. tamhiên III, XXXI, p. 213; III, XXXII, p. 215; NV, Apéndice, c. XIII, p. 342.

s Aurora, II, 142, en Obras Completas, ed. cit., pp. 112-114.

- Véanse a este propósito los comentarios de J. Starrobinski en la nota 1 a este texto (pp. 239-241) y de J. Derrida en su de la Grammatologie, Paris, Minuit, 1967, cap. 3, pp. 244.272.

17 M. Weber, Economia y sociedad, México, FCE, 4." reimp, 1979, p. 494. Cfr. K. Marx, Manuscritos, Madrid, Alianca, 1969, p. 169

"A, de Tocqueville, La democracia en América, vol, 11, 3. ${ }^{\circ}$ parte, cap. 1, Madrid, Alianza, 1980.

1: K. Ansell-Pearson, Nietzsche contra Rousseau, Cambridge University Press, 1991, pp. 67-68. 